subnormal hepatic function in the process of living (Heyd (I937), Hurst (I938)). Recent work has suggested that pre-operative diets containing protein rich in sulphur amino-acids (such as casein) and carbohydrates would appear to be of value in protecting the liver from the further injury inevitably inflicted by operation. The great difficulty, of course, is that there is no known test for liver function that is universally applicable to determine reduced hepatic efficiency. This is not surprising when the great number of functions the liver performs is considered. Further, in various conditions and under different conditions of nutrition, these functions are not affected to the same extent by noxious agents. Nevertheless, from a clinical point of view, results obtained by some of the modern tests, taken in conjunction with the clinical appearances, are valuable.

It is not possible here to discuss or to attempt to evaluate the various tests employed, but the performance of several different tests is probably the ideal. However, for clinical purposes, provided renal function (shown by blood urea) is normal, the hippuric acid synthesis test devised by Quick has been found to be satisfactory in evaluating surgical risk in either the jaundiced or non-jaundiced patient. The test depends on the ability of the liver to conjugate benzoic acid and amino-acetic acid. In the oral method 6 gms. of sodium benzoate are given in water by mouth, and the hippuric acid estimated gravimetrically in the urine passed in the next four hours. Values of $2 \cdot 6$ to $3 \cdot 3$ gms. (as benzoic acid) are considered normal. Rosenberg et al. (I94I) suggests that in slight degrees of hepatic damage an increased excretion may be obtained. It has been found that if less than I. $5 \mathrm{gms}$. of benzoic acid is excreted, the prognosis is bad, and few patients survive operation.

The value of repeated blood bilirubin estimations has been mentioned earlier in this paper.

Finally, in spite of the limitations of liver function tests, for none are infallible, present experience does show that where they are employed as a routine they have yielded results that have proved well worth while. In my view, the time is not far distant when tests for liver function in biliary disease will be considered by operative surgeons as essential as renal efficiency tests in renal disease.

\title{
REFERENCES
}

WOLFER, J. A., "The role of the pancreatic juice in the production of gall-bladder disease," Surg., Gynec. and Obst., 53, 433-447, I93 ARONSOHN, H. G., and ANDREWS, E., Experimental cholecystitis, Jena, G. Fischer, I909.

WHIPPLE, A. O., "'The surgical treatment of typhoid carriers," Ann. Surg., 90, 63I-642, 1929.

MACKEY, W. A., Brit. J. Surg., 24, 570.

ANDREWS, E., SCHOENHEIMER, R., and HRDINA, L., "Etiology of gallstones," Arch. Surg., 25, 796-8ro, r932.

RAVDIN, I.S., RIEGEL, C., JOHNSTON, C. G., and MORRISON, P. J., "Studies in biliary tract disease,"J.A.M.A., 103, I5O4, I934. ROUS, P., McMASTER, P. D., and DRURY, D. R., "Genesis of gallstones in the dog," Proc. Soc. Exper. Biol. and Med., 20, $3 \mathrm{I} 5$. I923.

HURST, A. F., "Disorders of the gall bladder," Guy's Hosp. Gaz., 49, 2 16, 1935.

DOWLING, G.' A., "Dyspepsia due to gall-bladder disease," J.A.M.A., 92, 7, I929.

LYON, B. B. V., Non-surgical drainage of gall tract, Philadelphia, Lea and Febiger, 1923

FIDLER, A., INNES, J., DAVIDSON, J. S. P., B.M.J., 2, 866, I94I.

RAVDIN, I. S., "A consideration of some problems of biliary tract disease," Proc. Inst. Med., Chicago, 14, 173, 19+2.

HEYD, C. G.,, "Liver deaths and the complications of gall-bladder surgery, South Surgeon, 6, I83, 1937.

HURST, A. F., B.M.J., 1, 661, I938.

QUICK, A. J., "The synthesis of hippuric acid: A new test of liver function," Am. J.M. Sc., 185,630, I933.

ROSENBERG, D. H., SOSKIN, S., Am. J. Dig. Diseases, 8, 425, I94I.

\section{SOME ASPECTS OF THE CLINICAL DIAGNOSIS OF ACUTE AFFECTION OF THE GALL BLADDER AND BILE DUCTS}

\author{
By ALEXANDER CRUICKSHANK, M.A., M.B., F.R.C.S. \\ (Assist. Surg., Prince of Wales Hosp., Tottenham, Queen's Hosp. for Children; Surg., Acton, \\ Teddington, Richmond Hosps., etc.; Surg. to E.M.S.)
}

It has been established by exhaustive researches into the medical history of disease of the $\stackrel{\mathscr{Q}}{?}$ biliary apparatus that the first mention of gall-stones and acute liver disease was made by a 0 Greek physician in the fifth century. His writings were published much later, in fact, in the 
sixteenth century, and in them we find the statement "dried-up humors concreted like stones," and he considered that they had something to do with "obstruction of the liver."

Later in the mediaeval literature we find descriptions of calculous cholecystitis associated with impaction of stones in the cystic duct (fourteenth century), and many reports appear with attempts to correlate symptoms with necropsy findings (early sixteenth century).

Vesalius (I5I4-I564) gives us excellent descriptions of actual stone impactions and abscesses involving the portal vein.

A French surgeon-Fernel (I58I) - gives a splendid account of "acute obstruction, calculus, fullness and emptiness of the gall bladder with sluggish action of the bowels, white faeces, reddish urine, and bile diffusions with the blood throughout the whole body, disfiguring the skin with jaundice" (Walters and Snell) (I940). (1)

Throughout the seventeenth and eighteenth centuries much increased knowledge was gained by faithful observers like Glisson and Sylvius, but the latter rather confused the writings of the time by thinking that the bile was formed in the gall-bladder and poured into the liver through the cystic and hepatic ducts.

Portal (I8I3), Trousseau, Charcot, Osler, and others bring lis up to the modern era, when the surgical adventures into the biliary field became more than pioneer work.

We then find that although an attempt had been made in I6I 8 by Johann Fabricius to drain the gall-bladder, it is doubtful if this was performed on a living patient.

Jean Louis Petit (I674-I750) gives the first authentic record of incising the abdominal wall to allow the exit of pus and stones from the gall-bladder.

Later, Graves, Sebastian and Thudichum perfected a two-staged operation which was intended to avoid the serious risk of opening the peritoneal cavity without first producing adhesions. Bobbs in America (I867) and Lawson Tait in this country (I879) both laid the foundations of the modern technique of cholecystostomy.

Then we find ourselves in the realms of such masters of advancement as Sims, Kocher, Mayo-Robson, Moynihan, and the Mayos (I892), and recently the late Sir David Wilkie, and at the present time Grey Turner and Pribram.

This obviously incomplete survey of the history of cholecystic diseases can be amplified with extreme interest in the writings of Osler, The Evolution of Modern Medicine, W. R. Bett, A Short History of some Common Diseases, R. H. Major, Classic Descriptions of Diseases, and many others.

\section{Incidence of Acute Cholecystitis and Cholelithiasis}

There is no question that the war years have definitely produced conditions which have lowered the incidence of these troubles. It has been said that industrial communities rather than agricultural ones are more prone to these maladies, probably mainly on account of the high vegetarian diet of the latter class. It also appears that Japanese, Russians, and central tropical dwellers are less prone than the countries with large urban populations like America, France, Germany, and this country (Walters and Snell). It may be, however, that diagnostic facilities make geographical differences in incidences more imaginary than factual. There is no doubt about the fact that there is a female preponderance of three to one, and of course pregnancy is blamed (2). It is claimed, for example, that in one series 75 per cent of patients who came to operation for gall-stones had been pregnant, but it has been shown that even in young people, when pregnancy has played no part, females show a special predisposition, for example, typhoid cholecystitis, is said to be twice as common in girls.

As life advances, the ability and inclination of the individual to take exercise play a role. Sedentary occupations, more interests in the pleasures of the festive board, and carelessness with regard to constipation and increase of weight all exert an influence which lowers the ratio from three to one to two to one or lower.

\section{Causation of the Damage to the Gall Bladder and Biliary Passages}

These can be studied under three heads:-

(I) Infection.

(2) Interference with cholesterol matabolism.

(3) Mechanical, chemical, and toxic agents. 


\section{Infection.}

This can occur by five routes-

(a) Extension from a neighbouring organ.

(b) Ascent through common and cystic ducts.

(c) Via the portal vein, the liver, thence to the gall-bladder by the lymph channels.

(d) From adjacent visceral lymphatics.

(e) Through the hepatic artery.

(a) Direct infection can possibly occur from perforation of a duodenal ulcer or other ulcerative conditions of the intestine, such as typhoid fever (3).

(b) Ascending infection through the ducts is of course the route most suspect, but it has been found that the introduction of large numbers of virulent organisms into the duodenum has not produced acute cholecystitis. It may thus be inferred that the gall bladder mucosa. is resistent to infection, and the bile itself possesses a definite sterilising power. The sphincter of Oddi and the presence of hydrochloric acid in the gastric contents are sufficient safeguards against acute biliary infection, even in the presence of some degree of duodenitis.

(c) MacCarty and Jackson (4) showed that a very common source of infection is the portal blood system and lymphatic channels. The association which is noted very commonly at operations-a localised hepatitis and cholecystitis-supports the view that the liver acting as a filter transfers organisms from the intestines to the lymphatics in its capsule.

(d) Various other venous and lymphatic channels and connections with the gall-bladder may be a likely cause.

(e) Rosenow (5) produced an acute cholecystitis in animals by the intravenous injection of streptococci from tonsils and teeth, and various other observers noted that infection in some cases could be traced to a pre-existing focus somewhere in the mouth or intestine. Wilkie and Burton noted that cases of acute cholecystitis occurred not uncommonly in persons suffering from sub-acute bacterial endocarditis (Walters and Snell).

The bacteriology of the inflamed biliary passages has been carefully studied and the bacillus coli ranks first; the streptococcus next, and staphylococci come third, as the causal organisms. The pneumococcus has been found in severe and acute cases. Other organisms, such as B. pyocyaneus, B. typhosus, and B. welchii, are occasionally found.

\section{Interference with cholesterol metabolism.}

Cholesterosis of the gall-bladder was first noted by Moynihan (6). He called it "a disease of the gall-bladder requiring cholecystectomy." It is very common to find this condition which has come to be known as the "strawberry gall-bladder," and it is due to the deposit of cholesterol esters in the lining of the viscus. The tendency at the present time is to consider that the mucosa absorbs the excess of cholesterol from the bile (Boyd) rather than it excretes cholesterol into the bile (Taussig) (7).

The question of dietetic and metabolic influences on the blood cholesterol content is still under constant study. Various conditions are known which raise the blood cholesterol, and pregnancy is the chief one cited. Debility following infections, nephritis and any condition causing a lowered metabolic rate, have been mentioned as factors present in high cholesterol blood values (Walters and Snell).

Suprarenal cortical hypertrophy and corpus luteum activity have also been suggested as causes. It has not definitely been established that dietary factors are of vital importance in any way.

The relation of pregnancy to the gall-bladder's reaction to cholesterol is complicated by the increased stasis in the whole organism and other functional disturbances. It has been found that cholecystograms done on a large series of pregnant women showed a high percentage of poor dye concentrations and that a palpation of the gall-bladder in Caesarian section cases in 75 per cent the gall-bladder was tense and could not be emptied (Walters and Snell).

\section{Mechanical, Chemical and Toxic Factors.}

Undoubtedly, some sudden disturbance in the power of the gall-bladder to evacuate its contents plays a large part in acute disease. This may arise from spasms of the sphincter of Oddi 
or of the unstriped muscle at the neck of the gall-bladder. Incoordination of the delicate mechanism at the ampulla may under certain conditions cause a regurgitation of pancreatic juice up the common bile duct and an acute cholecystitis ensue. It must be stated, however, that infection, metabolic nor mechanical defects cannot complete the picture, although any one of these factors may apply in any given case, and they are useful backgrounds when one is presented with a case for diagnosis.

\section{APPROACH TO DIAGNOSIS}

The approach to the diagnosis of acute lesions of the biliary apparatus can be studied under the following heads:---

(I) A careful and comprehensive history taking.

(2) A review of the patient's symptoms.

(3) The results of physical examination.

(4) Laboratory methods.

\section{History.}

In history taking there is no class of case so prone to mislead as the "acute gall-bladder." Many patients understate their case and many exaggerate their symptoms, as they are often victims of bilious attacks, fibrositis, intestinal irregularities, menopausal troubles, and many other maladies, real or imaginary, which may sidetrack the observer's thoughts.

Everything about the patient must be taken into consideration: habits, temperament, and status in life. It seems that certain families show a high incidence of cholecystitis, but it is doubtful if heredity plays an important part, except in so far as some families seem predisposed to such metabolic disorders as migraine, diabetes and obesity, and in these biliary disease occurs with an unusually high frequency. Previous infections, such as catarrhal jaundice, typhoid fever, pneumonia, appendicitis, have all been noted, but their causal relationship, if any, is difficult of proof, as also is the much disputed relationship of oral infection.

The high incidence in multipara has been remarked upon, and it is known that hypercholesterolaemia exists for a long time into the puerperium (Walters and Snell).

The phrase "fair, fat and forty" should not be allowed to guide us away from the diagnosis in individuals who do not come into this category, but it is a noteworthy fact that it is very seldom proved wrong.

\section{Symptoms.}

Acute onset of pain is the prime symptom. Patients describe it in various ways- "acute indigestion," "a tearing pain round to the back," even lumbago. The pain, however, is usually located in the right upper quadrant of the abdomen, and the characteristic indications to the right subscapular region, interscapular area or tip of the right shoulder are not often present in the early stages of an attack. Occasionally, the localisation may be mainly epigastric and rarely left hypochondriac. Sydenham described the pain as if "the body were drawn by a bandage or else a boring pain as if pierced with an augur. This at times remits, at times becomes exacerbated as the pain increases, the more it fixes itself to a point." Flatulence, belching, nausea, later vomiting and characteristically uncontrollable retching then appear, and there are often complaints in difficulty in taking a breath. The attack is accompanied by jaundice, which usually appears in twenty-four to forty-eight hours if stones are present, in which case, too, the features of a colic are manifest, with the patient writhing in agony, sweating, and in all stages of typical colic collapse. It is most unlikely that a true biliary colic would ever be confused except with a renal colic, but the less severe type of case may be simulated by individuals the subiect of acute constipation and reflex pyloric spasm, and also by very nervous areophagics.

Some cases of peptic ulcer with acid eructations may also simulate. The type of individual with migraine followed by epigastric pain, nausea and vomiting, and in many instances an obvious hypochondriac is a very difficult problem, especially as many cases of cholecystic disease develop features of hypochondriasis and evaluation of symptoms thereby rendered difficult. 


\section{Physical Signs.}

It is unfortunate that in many cases of acute gall bladder disease the severity of the lesion is in no way related to the degree of the objective signs. Many surgeons have noted that gangrene and even perforation of the gall-bladder may be present at operation when the pain is never even localised, and the signs of inflammation of an intraperitoneal viscus been very slight indeed. Conversely, severe pain and excruciating local tenderness may be produced by subsequently proved minor pathology in the gall-bladder.

The signs are a palpable tender mass in the region of the ninth costal cartilage, local sensitiveness, and hyperaesthetic band in the tenth dorsal space posteriorly; a catch of the breath on palpitation at the height of inspiration (Murphy sign); increasing rigidity with a rise of temperature and pulse rate. Much reliance can be based on a combination of these signs. It is impossible to recognise the transition stages from catarrh to suppuration and gangrene, but it may be said if the signs enumerated above be associated with a slight icterus of the conjunctiva, the diagnosis of acute cholecystitis, probably calculous can be made with certainty, and if the temperature becomes high and intermittent with profuse sweating and gross rigidity an empyema of the gall-bladder may be strongly suspected.

It is well to make it a rule to examine the patient first recumbent and afterwards sitting up, supported by the left arm. This relaxes the recti muscles to some extent, and a palpable distension of the gall-bladder may be found by "dipping" the right hand below the costal margin. Enlargement of the gall-bladder is often noted after the acute attack of pain has somewhat passed off.

\section{Laboratory Findings.}

(I) Examination of the blood.

(a) Leucocytosis is confirmatory evidence of inflammatory lesion, but is of little special diagnostic value.

(b) Sedimentation rate.-A rapid rate in acute cases is said to have a value in estimating the state of the disease and prognosis (Walters and Snell).

(c) Wassermann reaction should be done as hepatic syphilis may give rise to a very similar picture, and in this condition a strongly positive Wassermann is the rule.

(2) Examination of the Urine.

The presence of bile is of little diagnostic help beyond confirmatory evidence that jaundice has supervened. A temporary glycosuria may have some significance when a pancreatic lesion is suspected.

(3) Examination of Gastric Contents.

It has been stated for a long time that achlorhydria or a lowered acid are common in gall-bladder disease, but it cannot be shown that such a finding has any importance diagnostically.

(4) Liver Function Tests.

These are of no value in an uncomplicated acute case, but a high direct Van den Bergh reaction occurs in a considerable number of patients suffering from acute cholecystitis and biliary colic long before jaundice has occurred or a stone become impacted in the common duct (Walters and Snell).

(5) Duodenal Drainage.

This method was introduced by Lyon (8), and has been extensively tried out at the Mayo Clinic by introducing magnesium sulphate solution 25 per cent, or olive oil through the duodenal tube after an injection of pituitrin. A specimen of gall-bladder bile can be obtained and subjected to the following tests:-

(a) Physical examination for the presence of pus, biliary sand, or calculi.

(b) Cytological examination for the presence of cells of the gall-bladder mucosa, red blood cells or leucocytes.

(c) Examination for crystals of cholesterol and calcium bilirubin. "If found together the diagnosis is 90 per cent accurate" (Walters and Snell).

(d) Bacteriological studies of the bile removed by duodenal intubation are in con- 
clusion. This is only to be expected as direct cultures after removal of an acutely inflamed gall-bladder do not often yield satisfactory bacteriological results.

(e) Chemical examination of the bile.--The work of Lyon, Chiray, and Pavel (9) have shown that it is difficult to correlate the findings to be of any value in diagnosis as dilution and other unavoidable errors in estimation creep in.

The method of duodenal drainage as a diagnostic procedure has always entirely given way to cholecystography so ably worked out by Graham (Radiology, 1933).

\section{DIFFERENTIAL DIAGNOSIS}

When we come to consider the diagnosis from a differential point of view the most important problems to be faced are the following:-

(I) Acute Appendicitis, especially of the high retrocaecal type, presents the most worrying difficulty at times, but there is often a tell-tale intestinal odour in the breath and the tongue is more often brown and furred. A careful outlook for the special hyperaesthetic area, in the tenth dorsal space (Boas), and perhaps delay for a short period before advising operation will be beneficial so that localisation of tenderness and rigidity may become more obvious in the upper or lower quadrant of the abdomen.

(2) Acute Perforation or Penetration of a Peptic Ulcer.--The antecedent history of a dyspepsia of the nature of a peptic ulcer, "boarding" of the upper abdomen, the lowering or loss of liver dulness, and X-ray evidence of air in the subdiaphragmatic area may help this problem.

(3) Acute Pancreatitis is a rare disease, but may be a dangerous sequela of acute or chronic pathology in the biliary channels.

The diagnosis is often impossible in the more subacute cases, but a shift of the tenderness to the left and left shoulder pain accompanied by a considerable degree of shock may point to pancreatic haemorrhage or suppuration.

(4) Acute Upper Intestinal Obstruction may be very difficult to exclude in cases of persistent vomiting and early onset of distension, but again the appearance of an "intestinal facies," succussion splash in the abdomen, and auscultatory evidence of vigorous and painful peristalsis may decide the issue.

(5) Right Lower Lobar Pneumonia and Diaphrag̉matic Pleurisy are rarely mistaken at the present time.

(6) In pregnant women acute renal lesions like pyelitis, pyelonephritis, and even pyonephrosis have to be excluded.

(7) Renal Colic usually presents features of radiation to the loin and groin associated with disturbances of micturition.

(8) Acute Infective Hepatitis of amoebic or syphilitic origin may be confused with cases of acute disease of the gall-bladder with impacted calculi which have progressed to the grave condition known as acute cholangitis: here, constitutional symptoms, such as bouts of high fever, variable jaundice, and rapid deterioration of the patient's condition occur, with remissions, and generally an unfavourable course.

Grey Turner has pointed out the care which must be taken to evaluate the symptoms correctly when a patient presents with an obvious external lesion like an umbilical hernia. The hernia may be operated upon with little relief to the patient if acute cholecystitis or cholelithiasis has been the crucial factor. $\mathrm{He}$ states that "if a hernia is at fault, then as a rule the attacks of pain are associated with discomfort in the hernia, or the hernia gets bigger and harder during the attacks" (10).

(9) Coronary Thrombosis presents one of the most difficult problems at times, but it may be remembered that:-

(a) It is much commoner in males.

(b) The pain of acute biliary disease rarely radiates to the arms. 
(c) Pain of coronary occlusion rarely radiates to the back.

(d) Signs of falling blood pressure and cardiac failure may rapidly ensue.

(e) Electro-cardiography can quickly determine a coronary infarct in cases of doubt.

These points may be of value in elucidating the problem where the two conditions may simulate each other or co-exist, a fact which has received much attention of recent years.

\title{
Summary
}

I. A short account of the medical and surgical history of biliary disease has been given.

2. A discussion of the etiology has been briefly presented under the headings-infection, cholesterol metabolism, and mechanical, chemical and toxic factors.

3. A review of the symptomatology, physical signs, and clinical laboratory, data and their diagnostic value has been made.

4. A series of the chief differential diagnostic problems met with in practice has been presented in which appendicular disease, peptic ulceration, pancreatic disease, and coronary occlusion have been shown to give rise to the greatest difficulties.

\section{REFERENCES}

I. Diseases of the Gall Bladder and Bile Ducts, Walters and Snell (1940). I have made wide refe nce to this excellent and exhaustive research and owe much to it for valuable information and for an introduction to special works.

2. HUGGINS, "A Study of the Relationship of Pregnancy to Disease of the Gall Bladder," Surg. Gynaec. and Obest., October I935.

3. A. E. MORRISON, B.M.J., December 20 , rgr3.

4. MACCARTY and JACKSON, "The Relation of Hepatitis to Cholecystitis," Minnesota Med., June I921.

5. ROSENOW, "The Etiology of Cholecystitis and Gall Stones and the Production by the Intravenous Injection of Bacteria," Collection Papers of Mayo Clinic, rgr6.

6. MOYNIHAN, "A Disease of the Gall Bladder requiring Cholecystectomy," Ann. Surg., December I9o9.

7. BOYD, "Studies in Gall Bladder Pathology," Brit. Journ. Surg., January 1923.

8. LYON, Non-surgical Drainage of the Gall Tract, 1923.

9. CHIRAY and PAVEL, "Physiology of the Lyon Test," Am. J.M. Soc., I926.

Io. GREY TURNER, Proc. Med. Soc., London (Volume LXII, I939).

\section{THE CLINICAL DIAGNOSIS OF CHRONIC GALL-BLADDER DISEASE}

\author{
By A. G. GIBSON, M.D., F.R.C.P. \\ (Censor, Royal Coll. Physicians, London; Physician, Radcliffe Infirmary, Oxford)
}

\section{Symptoms}

Chronic cholecystitis usually presents itself as gastritis, flatulent dyspepsia or indigestion. In the past these terms satisfied us as definite entities, but not so now; we want ocular demonstration or some more definite proof before we accept them as the true diagnoses. Chronic cholecystitis is more common in women than men, and affects those in middle life or in the 5o's. Women that are fat are more affected than those that are thin, also those that have taken little exercise and have been indulgent as regards food are more likely to be affected than the thin ascetic type. But no age, except perhaps young children, can be looked upon as exempt. The dyspepsia of chronic cholecystitis, despite the difficulties of diagnosis, has certain features which can often be recognised by a careful history, or at least one can, by this means alone, be suspicious that the gall-bladder is not in a healthy state. The indigestion of chronic cholecystitis is often an epigastric discomfort, a fullness or a slight nausea which comes on after food-and often after the most carefully prepared and simple meal. It is often quite irregular in the time at which it comes on, and, unlike gastric and duodenal ulcer, is not 